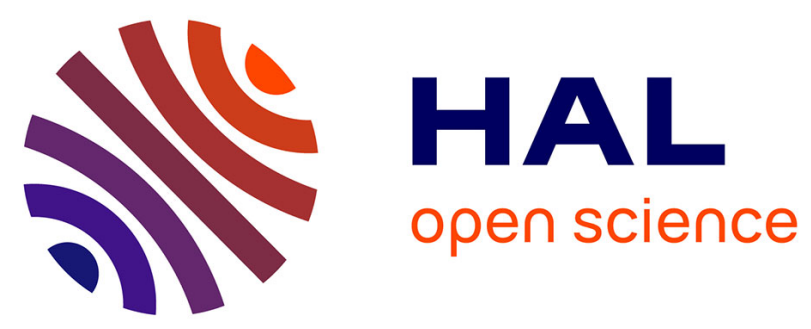

\title{
Collaborative network with SMEs providing a backbone for urban PSS: a model and initial sustainability analysis
}

\author{
Alan Lelah, Fabrice Mathieux, Daniel Brissaud, Lucien Vincent
}

\section{To cite this version:}

Alan Lelah, Fabrice Mathieux, Daniel Brissaud, Lucien Vincent. Collaborative network with SMEs providing a backbone for urban PSS: a model and initial sustainability analysis. Production Planning and Control, 2012, 23 (4 April 2012), pp.299 - 314. 10.1080/09537287.2011.627660 . hal-00653741

\section{HAL Id: hal-00653741 \\ https://hal.science/hal-00653741}

Submitted on 20 Dec 2011

HAL is a multi-disciplinary open access archive for the deposit and dissemination of scientific research documents, whether they are published or not. The documents may come from teaching and research institutions in France or abroad, or from public or private research centers.
L'archive ouverte pluridisciplinaire HAL, est destinée au dépôt et à la diffusion de documents scientifiques de niveau recherche, publiés ou non, émanant des établissements d'enseignement et de recherche français ou étrangers, des laboratoires publics ou privés. 


\title{
A Collaborative Network with SMEs Providing a Backbone for Urban PSS: A Model and Initial Sustainability Analysis
}

\author{
Alan Lelah ${ }^{1}$, Fabrice Mathieux ${ }^{1}$, Daniel Brissaud ${ }^{1}$ and Lucien Vincent ${ }^{2}$ \\ ${ }^{1}$ Grenoble University, G-SCOP Laboratory, 46 av Félix Viallet, \\ 38000 Grenoble, France \\ alan.lelah@g-scop.grenoble-inp.fr \\ 2 ENSM SE, Institut Henry Fayol, équipe MESPROD, 158 cours Fauriel, \\ 42023 Saint Etienne Cedex2, France
}

\begin{abstract}
High-technology SMEs have regularly shown their capacities for creating and developing innovative services. However, their reduced size often confines them to vertical applications and limits the possibilities for broader development. Strategies grouping SMEs into collaborative networks are possible but sometimes need a strong leader to ensure credibility. On the other hand, large integrator-operators cannot be proficient in all the necessary domains, particularly when applications move very fast. They very much need the diversity and the dynamics of these SMEs to provide service packages with a common service backbone. Uniting the different actors is a challenge displaying good promises from various perspectives including sustainability. However it is necessary that the links between the different partners and their corresponding activities be correctly represented in a model to be understood. This paper proposes a new model for activities and processes in firms collaborating together in a network. The clearer understanding of organization acquired with the model is then used to discuss sustainability issues within the network.
\end{abstract}

Keywords: collaborative networks, sustainability, PSS, SOA, SME, model

\section{Introduction}

\subsection{Innovation in Highly Dynamic Markets}

The European Commission (EU, 2009) noted that Small and Medium Enterprises (SME) play an important role in European industry. Small high-technology firms have often proved their capacity for creating innovative services, especially in the field of Information and Communication Technologies (ICT). Their small, flexible structures are well-adapted for converting new ideas into marketable projects and services to be deployed rapidly in changing markets. They have core-skills that make them very competitive in specific areas. However they often lack the scale needed to introduce their new technologies and their size can be a handicap for developing complex systems requiring complementary multidisciplinary know-how. It is not always easy to penetrate markets. The SMEs have to join their efforts together in order to overcome these limitations through collaboration (Camarinha-Matos et al. 2009).

On the other hand, large operator-integrators cannot be proficient in all the different fields they would need to cover in a rapidly changing world. High-technology applications can move too fast to adapt their strategies. They should lean on SMEs as reliable subcontractors, providing innovation and research compatible with the operators' core activities.

\subsection{Backbone for Services}

Often, multiple services covering similar geographical locations draw on identical backbones, or infrastructures, for ICT, facilities and other purposes. It seems logical that instead of piling up technologies to 
provide the services, there is more to gain through the mutualisation of common infrastructures. A backbone built for one application can be used for other services if it is sufficiently dimensioned. Indeed, any infrastructure will have a certain capacity to function correctly and cannot be considered as an unlimited source. In particular, the SMEs need support from an ICT backbone facilitating communication of data within the network. Local or regional institutions, be they public or private, are interested in systems that potentially reduce material and energy consumption in their region. Furthermore, once the service backbone set up, it would pave the way for other service possibilities.

Complementary SMEs collaborating together have the potential to build and run large, complex, dynamic systems. According to Simatupang and Sridharan (2005), supply chain (or network) collaboration can be defined as two or more enterprises working together to create a competitive advantage and higher profits than those that could be achieved alone. However, within the network, the quality of collaboration is important for long term considerations necessary to build a solid service backbone. Moreover, complexity and challenges are magnified for processes involving a network of organizations with different goals, capabilities and dependencies. In the end, success will depend on the effective coordination and integration of people, information and activities (Noori and Lee 2004).

A big operator-integrator is capable of negotiating and gaining the confidence of local authorities or other large companies and can guarantee long term viability. It would provide the driving force necessary to lead such a network. As the coordinator, it must manage the relations between the firms and the dynamics of the network. The common backbone must integrate the diversity of the smaller firms to provide novel service packages. A good understanding of the customer's operations and of the corresponding activities is necessary (Childe, 1998). Individual enterprises cooperating in the network will then be able to concentrate on their core competencies and this will help increase their competitiveness (Thoben and Jagdev, 2001). However, for fair and efficient cooperation the network must not be tied down to the red tape of the operator and the SMEs not simply relegated to the role of subcontractors.

\subsection{Sustainable Means}

At the same time, modern societies need to find a consensus on the development of the socio-environmental system as a whole (de Graaf et al. 1996). The Brundtland Report (1987) officialised the basis for sustainable development. Tomiyama (2001) explained that the post mass production paradigm sought to decouple economic growth from material and energy consumption. The move towards dematerialization has been amplified with the opportunities opened out by ICTs (Heiskanen et al. 2001) capable of providing monitoring systems allowing real-time adaptation of services and facilitating maintenance. New production models concentrating on environmental preoccupations such as industrial ecology (Lowe et al. 1995), eco-design (Brezet and van Hemel, 1997) and cleaner production (Fresner, 1998), have been proposed.

In the field of products and services, potentially sustainable models emerge, such as the extended enterprise concept (Childe, 1998), product service systems (PSS) (Tukker, 2004), the economy of functionality (Bourg and Buclet 2005), and service engineering (Sakao et al. 2006). Tan et al. (2009) considered PSS as innovation strategies where instead of focusing on the value of selling physical products, the focus is on the value of the utility of products and services throughout the product's life period. Sustainable product design goes beyond environmental optimization of the products and services (van Weenen, 1995). Tomiyama (2001) said that PSS were fundamentally sustainable; however, few studies have demonstrated the reality of the hopes they raised (Kimita et al. 2009).

Lelah et al. (2010) have reported the construction of a common backbone providing PSS in an urban setting. A collaborative network of SMEs behind an operator-integrator uses ICT to provide quality services to their clients. The environmental impacts of the structure were studied in depth (Lelah et al. 2011). However, for the project to be successful and sustainable, considering the complexity of the organization of the complete services, it is important that relations within the network, and towards the customers, first be clarified. 


\subsection{Contributions}

In order to build a competitive network based on SME-Integrator collaboration delivering PSS, a network model that clarifies the relative responsibilities, roles and activities of network partners is necessary. The model must take into account the service backbone to support interactions between collaborators and provide a common infrastructure capable of generating and supporting services in a highly dynamic market.

This article studies the case of a network of complementary SMEs behind a big operator-integrator in a collaborative network seeking to build a common backbone for environmental urban public utility services. It proposes a model to formalize the framework in a service-oriented architecture that can help clarify relations between the partners as they move from individual applications to a common backbone for services. The model describes how the different partners fit into the network and exchange services that generate activities and mobilise physical resources. The model is then applied to the case of glass waste collection. It draws attention to the fact that sustainability depends on the organization of activities built around physical objects and how these objects are used individually or collectively within the network. To understand this, the paper explores the conditions for the network to function correctly and enhance sustainable services.

Following this introduction, section 2 describes the transformation of the individual services within a common service backbone. The case of glass waste collection is then exposed. Section 3 proposes a model for PSS representation in collaborative networks. In section 4 the model is applied on the case study. Sustainability issues are discussed in section 5. Finally, section 6 concludes the article.

\section{A Common Backbone for Urban Services}

\subsection{Principles of Transformation to a Collaborative Network}

Services provided traditionally by local institutions, as in the case of city councils, hospitals or even private firms, undergo constant evolution. New possibilities open out with the introduction of business models such as PSS and innovative technologies like ICT (Heiskanen et al. 2001). Dynamic, innovative SMEs propose supporting services with novel high-technology products. For example, modern cities are equipped with sensors that measure environmental data like noise or pollution levels. The business model proposed is often a form of PSS with the sensors remaining the property of the SME providing the service (Lelah et al, 2010). Such applications are vertical when they propose a service offer within a specific field, for example environmental data, built around the core skills of the SME that runs the entire PSS alone. In a vertical organisation, the provider will run everything from the installation and operation of the sensor network to processing and presentation of results. The vertical organization is not optimal in terms of resources and the backbone could be used for other services if it is correctly dimensioned. Examining the case of glass waste collection offered by a municipal council in France, Lelah et al. (2011) suggested that the environmental impacts could be reduced with a common service backbone. The backbone structure is horizontal if it covers a large range of different applications. A good way of moving away from proprietary vertical-orientated applications towards open horizontal systems is to delimit a coherent geographical area, like urban districts, displaying a clear interest for a family of services. The services should cover a coherent field of activities, such as public utility services like waste collection, gas and water metering, noise and pollution measurements.

\begin{tabular}{|l|c|l|}
\hline \multicolumn{1}{|c|}{ Actor } & Acronym & \multicolumn{1}{c|}{ Role } \\
\hline Population & P & Final users (city citizens, patients, ..) \\
\hline Original Service Provider & OSP & Local town council, hospital, ... \\
\hline Operator-Integrator & O-I & Large firm: multiple service operator and integrator \\
\hline SME & SME & SME providing the novel service \\
\hline Service Provider & & SME providing the optimization service in the case study \\
\hline Urban Platform Host & & SME(s) housing the common service platform in the case study \\
\hline Telecom Operator & & O-I in the case study \\
\hline
\end{tabular}




\begin{tabular}{|l|l|l|}
\hline Gateway Operator & & SME providing gateways in the case study \\
\hline M2M linker & & SME providing local communications in the case study \\
\hline Sensor Operator & & SME running the sensor network in the case study \\
\hline
\end{tabular}

Table 1. Principal Actors Involved in the PSS Offer

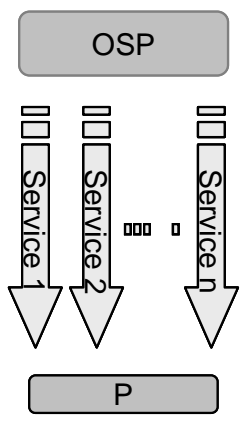

(a) OSP services

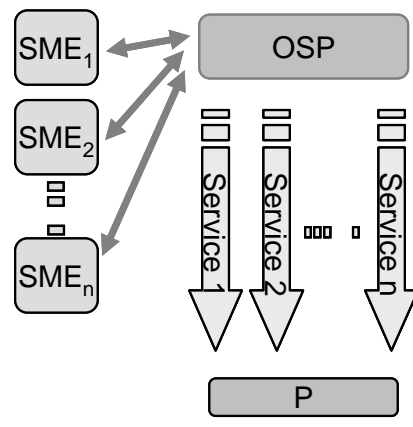

(b) SME Services

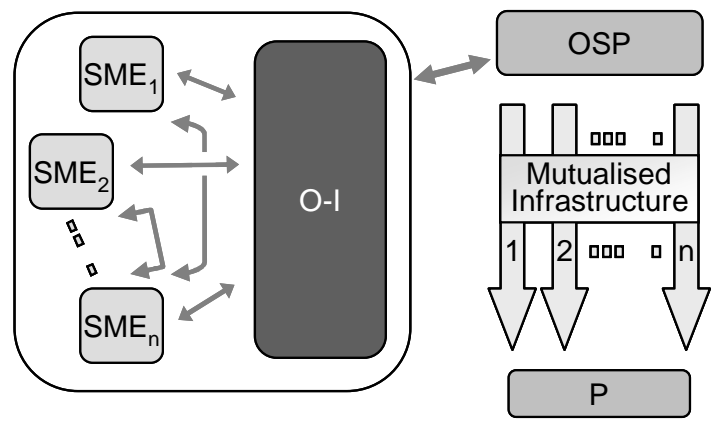

(c) Multi-Service Infrastructure

Figure 1: Transformation from vertical services to a multi-service backbone.

The transformation from vertical services provided by SMEs to a horizontal backbone for services is illustrated in Figure 1 and Table 1 lists the principal actors concerned. "OSP" is an Original Service Provider providing a family of vertical services to a Population "P" (Figure 1(a)). The couple, OSP-P, can be a regional council providing services to citizens; a hospital providing health services to patients, etc. As new technologies develop, the nature of the services change and the skills necessary to run them evolve. OSP can turn to specialized high-skilled SMEs (Figure 1(b)) for their know-how to support existing services and introduce new ones. High-tech applications will be advantageously proposed in the form of PSS in order to insure professional standards as well as the capability of adapting to technological changes. As complexity increases, the number of different SMEs can rapidly become significant and OSP has to deal with many different enterprises. A better solution is that the SMEs form a collaborative network piloted by a firm named the Operator-Integrator, "O-I" (Figure 1(c)). Childe (1998) explained that a company, with many suppliers and many parts to be brought together, begins to look like a set of cooperating partners. Organizational problems are now transferred to the network and OSP will deal directly with O-I instead of with multiple SMEs. When SMEs enter the group or leave it, this will be transparent for OSP and O-I will insure the continuity and the coherence of the group. It is clear that in view of its responsibilities, O-I should be a large, well established firm capable of gaining the confidence of OSP and P. However, even though the experience of O-I legitimates it's becoming the representative of the network, the organisation can become quite complicated and it becomes important to distinguish and clarify the different relations between the actors.

\subsection{Presentation of a Case Study on Glass Waste Collection}

\subsubsection{The SensCity Project}

An example of a collaborative network is the French project SensCity (Lelah et al. 2010), proposing a backbone for services in urban districts. SensCity brings together SMEs with a telecom operator (the operatorintegrator) and supports the backbone while providing different services such as optimization of waste glass collection or noise and pollution level measurement. The project was initiated to develop an environmentally friendly urban ICT backbone comprising of the sensor network and associated services. SensCity uses Machine-to-Machine (M2M) technologies to set up a telecom network. M2M means that machines exchange data with other machines and make decisions without human intervention. Basically sensors gather information from the urban environment and dispatch it to more powerful machines forming an urban M2M platform and 
service platforms capable of aggregating the data and providing services. In SensCity the M2M network covers the city supporting classical urban public utility services and enhances new services. SensCity brings together SMEs that formally provided vertical services into a collaborative network led by the telecom operator. In order to illustrate this type of transformation, the paper will present the case of glass waste collection in SensCity.

\subsubsection{The Waste Glass Collection Service}

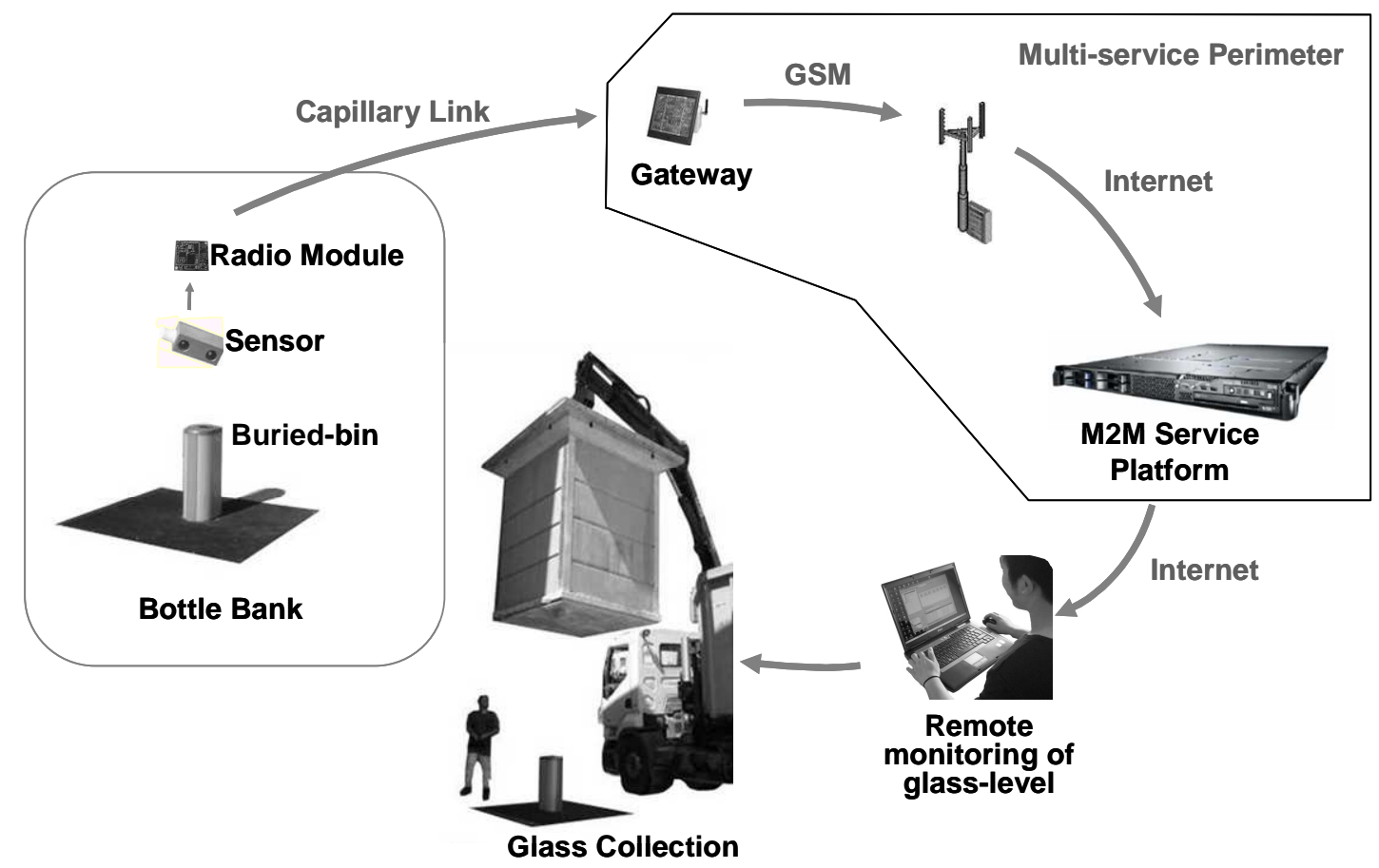

Figure 2: An M2M-enhanced waste glass collection service.

Many cities, today, provide bottle-banks for residents to dispose waste glass. Waste glass, or cullet, is discarded in bins and collected by pick-up trucks regularly. In the basic service scenario the trucks visit each bank systematically. The driver checks the level of the cullet in each bin and decides if it is necessary to empty it. He then drives on to the next bank. Starting from this basic scenario, collection can be optimized if the drivers already know which bins must be emptied. This is possible using sensors in an M2M network (Lelah et al. 2011). The principles of the M2M enhanced waste glass collection is illustrated in figure 2 . In the bottle-banks, the bins are equipped with ultrasound sensors that measure the level of the cullet. Communication modules link them to telecom gateways placed close by. The entire bottle-bank park is covered in this way and the data collected is relayed through the telecom network to an M2M service platform. The information is then aggregated and used to optimize the planning of the rounds of the collect trucks. The results of the optimization are sent to the waste collection company. 


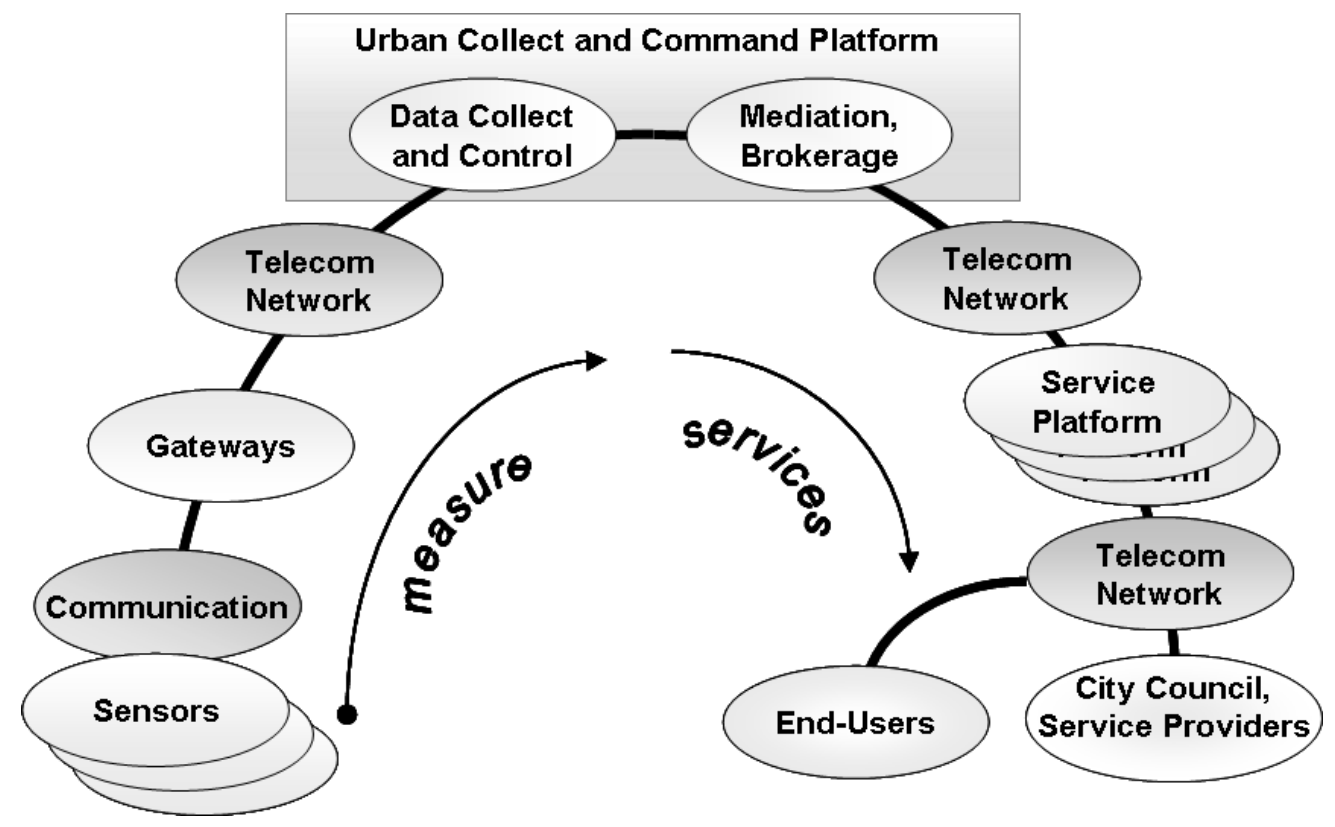

Figure 3: M2M services with a common service backbone.

Waste glass collection can be integrated within a service backbone using M2M techniques (Lelah et al, 2010). The overall architecture of the system is illustrated in figure 3. In the figure, data is collected on the left and the sensors are positioned in the city in order to meet service requirements. Different sensors and service platforms providing multiple services are shown. Basically the system is the same as before, but this time, before sending information for each application to the service platforms, a distinct urban collect and command platform treats the data, dealing with confidentiality, brokerage and other questions. Services are then deployed on the right. Different service provider platforms can be connected to the urban collect and command platform through internet and will pilot the different service offers. In this way the information is made available to local administrations and residents.

\section{A New Model for PSS Representation in Collaborative Networks}

The M2M backbone is too complex for a single enterprise to run alone. Multiple enterprises with complementary core competencies capable of proposing a large diversity of innovative applications have to work together to build and run it. The collaborative network is a good solution but a model to represent the system is necessary to integrate the links between the different service offers and the corresponding activities. Starting with a literature review, this section will propose a model to represent PSSs across a collaborative network.

\subsection{Literature Analysis}

A meta-level management process would help collaborative systems (networks) manage architecture, business processes and value propositions and create and sustain competitive advantages (Bititci et al. 2003). Porter (1998) established activity-based theories of a firm, providing foundations for thinking about strategy across multiple businesses. Within the value chain identified by Porter, primary business processes deal with the creation of the product, marketing and delivery while supporting business processes facilitate the development, deployment and maintenance of resources. The power of managerial processes is that they focus on activities 
while placing emphasis on how the activities are interconnected and how work flows through the activities to produce efficient and effective results (Bititci et al. 2011).

Processes in collaborative networks obviously concern all the different actors but although the importance of relationships is widely acknowledged, flawless coordination within the supply chain is difficult to achieve in practice and it is necessary to align business processes (Trkman, 2010). Detailed models are used to visualise control and coordination of business processes and the sequence and interaction amongst activities in highly dynamic, demand-driven supply chains (Verdouw et al. 2010). The context of B2B (business to business) relations within collaborative supply chains can be characterised by five dimensions: climate; structure; information technologies; lifecycle; and external context and appreciated performance through perceived satisfaction and perceived effectiveness (Derrouiche et al. 2010).

Moving to the frontier between products and services, Sakao et al. (2006) introduced service engineering. They underlined the need to articulate product and service approaches simultaneously. Appropriate ontology would help develop differentiated economic offers by improving flexibility and responsiveness of product and service development (Ki Moon et al. 2009). In order to facilitate service design, Shostack (1982) proposed the service blueprint. A blueprint is defined as a picture or map that accurately portrays the service system so that different people involved in its development could understand and deal with it objectively regardless of their roles or their individual points of view (Zeithaml and Bitner, 1986).

Shimomura et al. (2009) extended the notion of blueprinting to the case of PSS integrating both the product and the service to enhance simultaneous design. In order to represent both products and services for design purposes, Maussang et al. (2009) described PSS as a set of service units and physical objects, while Tomiyama (2001) said that artefacts were usually service channels or service contents. These representations are very efficient for modelling complex PSS. However, in the case of collaborative networks, the relative positions of the different partners-actors are not always easy to apprehend, making it difficult to identify and negotiate particular requirements for each actor. Service supply logics need organisational differentiation in order to function efficiently and optimize resources.

In conclusion, a model for a collaborative network of actors providing PSS should display the following qualities:

- Respect and illustrate the business processes involved.

- Facilitate the understanding of service activities and physical products.

- Identify the actors engaged at each stage of the PSS.

- Allow for different levels of granularity.

- Point out the relations between the actors and conserve this information in all the different levels of representation.

\subsection{The Proposed Model}

In order to clarify the complex organization of the collaborative PSS network and the roles of the different actors, this paper argues that the network can be viewed as imbrications of successive B2B PSS offers. The proposed representation is inspired by the previous models described above. It places greater accent on the relations between partners rather than the details of the service activities and the physical supports. It includes, wherever possible, standard notations of business process modelling such as recommended by Adonis ${ }^{1}$. Figure 4 illustrates the proposition to represent collaborative PSS networks.

\footnotetext{
${ }^{1}$ Adonis is a modelling software based on Business Process Modelling Language (BPML), edited by the BOC group located in Vienna (Austria)
} 


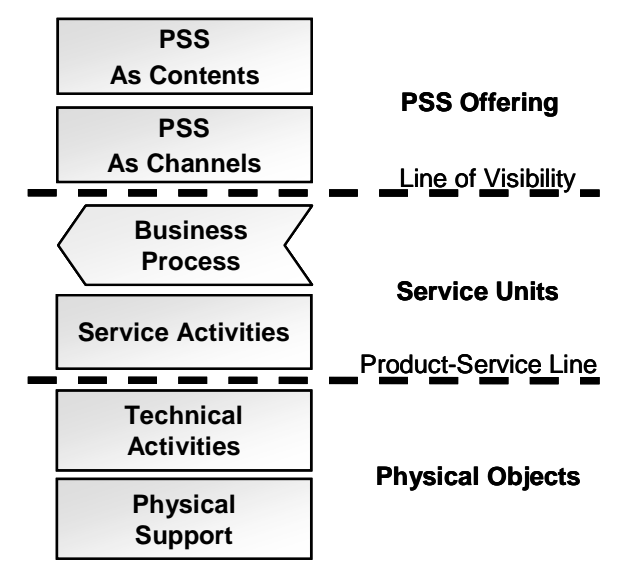

(a) Definitions

(PSS Content and Channel Offerings; Service Units; Physical Objects)

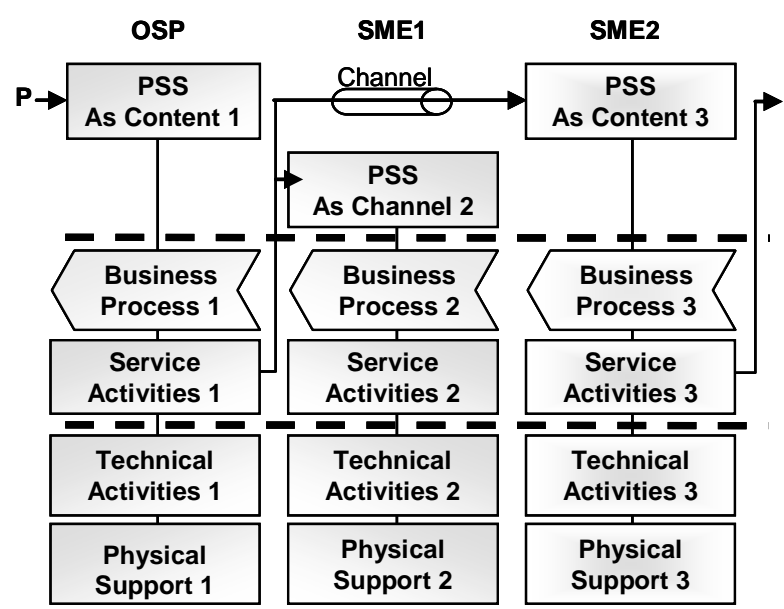

(b) Calls for Successive Services

(Original Service Provider (OSP provides a PSS to Population $(P)$; SME1 provides a chanel; SME2 provides content)

Figure 4: Representation of a collaborative PSS network.

Basically, in Figure 4(a), two horizontal lines separate three views of a PSS. Above the top line of visibility, the proposed PSS offer to customers is represented. Service contents and channels are distinguished at two different levels and in Figure 4(b) the channel is represented as a tube. Below this first line, the ProductService Line expresses the need for service and technical activities to fulfil the PSS. The organization of the offer is structured into Service Units and related Physical Objects. Operational processes are organized as business processes, represented in the Adonis model by arrow boxes. Different activities, represented in squares, are related to the business processes. The service units rely on physical objects to operate. The physical objects are physically represented in the physical support and require technical services to function.

This basic model is put into action in Figure 4(b). Similar to previous business process models (Adonis, $\mathrm{BPMN}^{2}$ ) vertical swimlanes identify different firms and other institutions. An arrow is used to represent a call for new PSS, going from the client or partner requesting the PSS to the offer. The PSS offer illustrates the business service as desired by the client or partner. The receiver requires a service and turns to the provider who supplies the service. The PSS offer must satisfy the needs of the receiver. In the case represented in Figure 4(b), OSP provides a PSS to P and calls on SME1 and SME2 for their help. SME1 provides a service channel and SME2 provides the contents. SME1 could be omitted from the diagram if it did not provide a particular value or play a particular role in the chain. Alternatively, the service channel can be represented as a physical object, below the product-service line, owned by the actor asking for the service. For instance a telecom company can be fully represented in a swimlane, or simply be included as a physical object representing a communication terminal (not shown in the figure), or omitted, depending on the importance of this service in the case studied.

Note that the example illustrated above has been simplified for high-level representation. It is possible to go deeper and detail the activities in the service units and physical objects as in the extended blueprints of Shimomura et al. (2009). However care must be taken not to lose the links between the firms implied when moving further down to in-depth analysis.

\section{Application of the Model to the Case of Waste Glass Collection}

Although the transformation from the basic glass collection into a common service backbone in the case of the SensCity project shows potential benefits for the environment (Lelah et al, 2011), the collaborative network is

\footnotetext{
${ }^{2}$ BPMN are specifications for modelling software by the Object Management Group, Inc. (OMG)
} 
more demanding and complicates the organisation of the different service offers. The proposed model can help understand the process and facilitate the organization of the network in order to reap the benefits.

\subsection{Basic Waste Glass Collection}

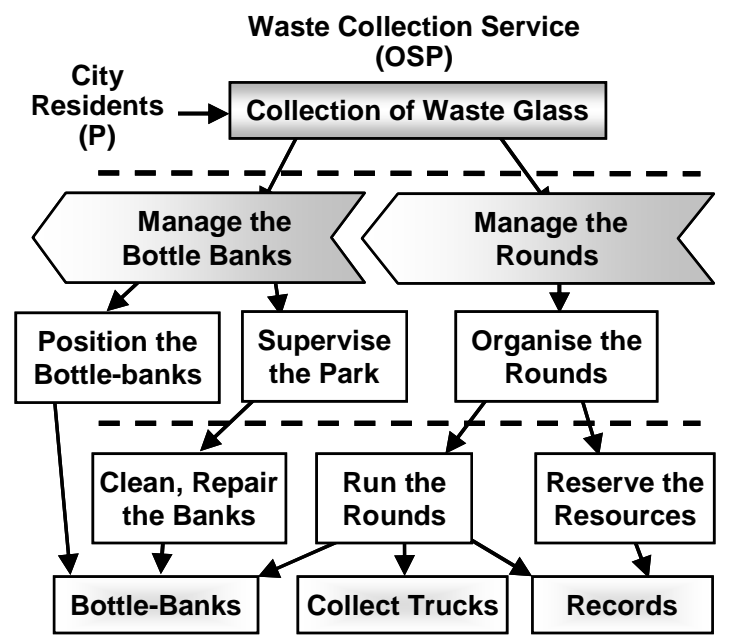

Figure 5: Urban waste glass collection service.

Traditionally, public authorities provide the waste collection services. Some of the more important activities of the service are represented in Figure 5. It can be noticed that this basic service is straightforward from OSP to P so the figure does not need to distinguish between channels and contents. P represents the city residents and OSP is the waste collection service run by the local council. The two major business processes in the service are illustrated: managing the bottle banks and managing the rounds. The direction of the arrow-shaped boxes shows successive stages of the overall business process provided by the waste collection service and indicates that managing the park requires that the rounds be managed. Managing the bottle banks includes supervising, repairing and cleaning the bottle banks. In the example, supervising is considered as a service activity, while repairing and cleaning the banks is a technical activity performed by the technical staffs that go to the banks. Another activity consists of positioning the bottle banks for logistic purposes. Managing the rounds requires the organization of the collect rounds. Resources have to be reserved and noted in the records. The rounds must be run and the trucks mobilized. 


\subsection{A Vertical PSS Offer for Glass Waste Collection}

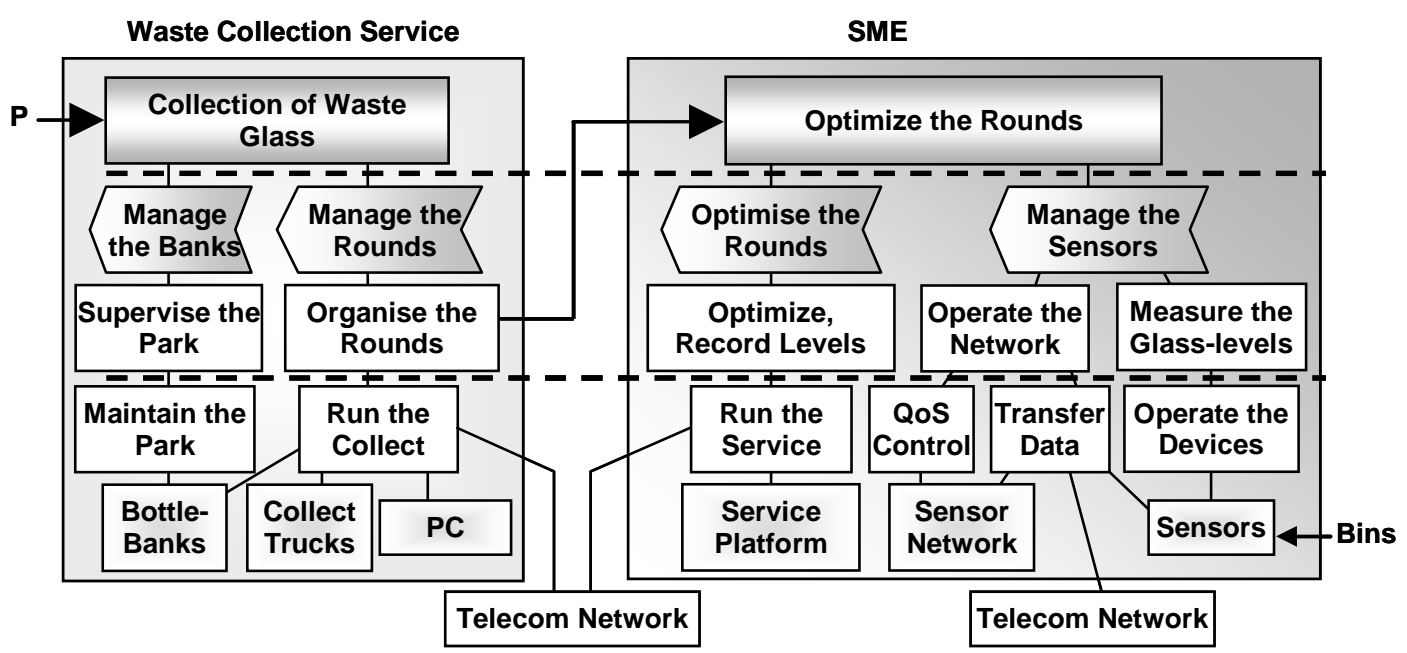

Figure 6: SME service-provider for glass waste collection.

An SME can provide supporting PSS to the OSP. Figure 6 depicts the vertical PSS initially proposed by the SME alone. The service and technical activities as well as the physical objects in the diagram have been simplified. The arrows calling on them have been replaced by simple lines. The figure shows how the SME is solicited by the waste collection service provided by the local authorities in order to satisfy the needs of the city residents. Communication between the SME and the waste collection service is made through internet provided by a telecom operator. However the operator provides standard telecom services and has no connection with the PSS offer. It is chosen to represent the telecom network as a simple resource. The SME optimizes the waste collection rounds. This requires daily information on the glass-levels that must be monitored by the SME. Technically it is necessary to operate the devices and insure data transfers. The SME operates the network and controls the Quality of Service (QoS). This means that measurements and communication within the sensor network function and that data is correctly transferred to the GSM network (Global System for Mobile Communication). It can be noticed that once the data enters the GSM network; the SME loses control and has to rely on the telecom operator for delivery.

Additionally, a service platform, with a server and supporting activities (not detailed in Figure 6), optimizes the collection rounds and conserves data. The SME uses classical telecom services to link the sensor network with the service platform and monitor the glass level in the bottle-banks. As before there is no particular interest in showing the operator that provides standard telecom services, it is sufficient to represent the network as a resource used by the SME. Out in the field, the SME manages the sensor network and gateways to ensure operation.

\subsection{Glass Collection with a Common Service Backbone}

A different structure is proposed by the collaborative network in the SensCity project. The organization of the services with a shared backbone is much more complex. New problems appear concerning proprietary issues and confidentiality. Also, the introduction of new firms and skills into the network opens new possibilities, like full end-to-end QoS coverage. This means that new intermediary services emerge in the network model.

In the SensCity consortium, different SMEs measure and collect data in the urban perimeter covered by the backbone. A broader variety of applications are proposed to the local authorities. Some of the SMEs run their own applications while others collect and provide raw data to SMEs specialized in services. Yet others deal with the local M2M wireless communication, including the protocols and insuring the evolution of these technologies in open state-of-the-art standards. Specialized SMEs provide gateway coverage. Other SMEs are implied in the running of an urban service platform. The platform collects and controls data coming from the 
sensor network; stocks and manages the data; insures brokerage; deals with legal questions concerning privacy and finally sends information to the end-users or other servers. The organization is complex and the proposed model depicted in Figure 7 helps clarify the relations between the different partners.

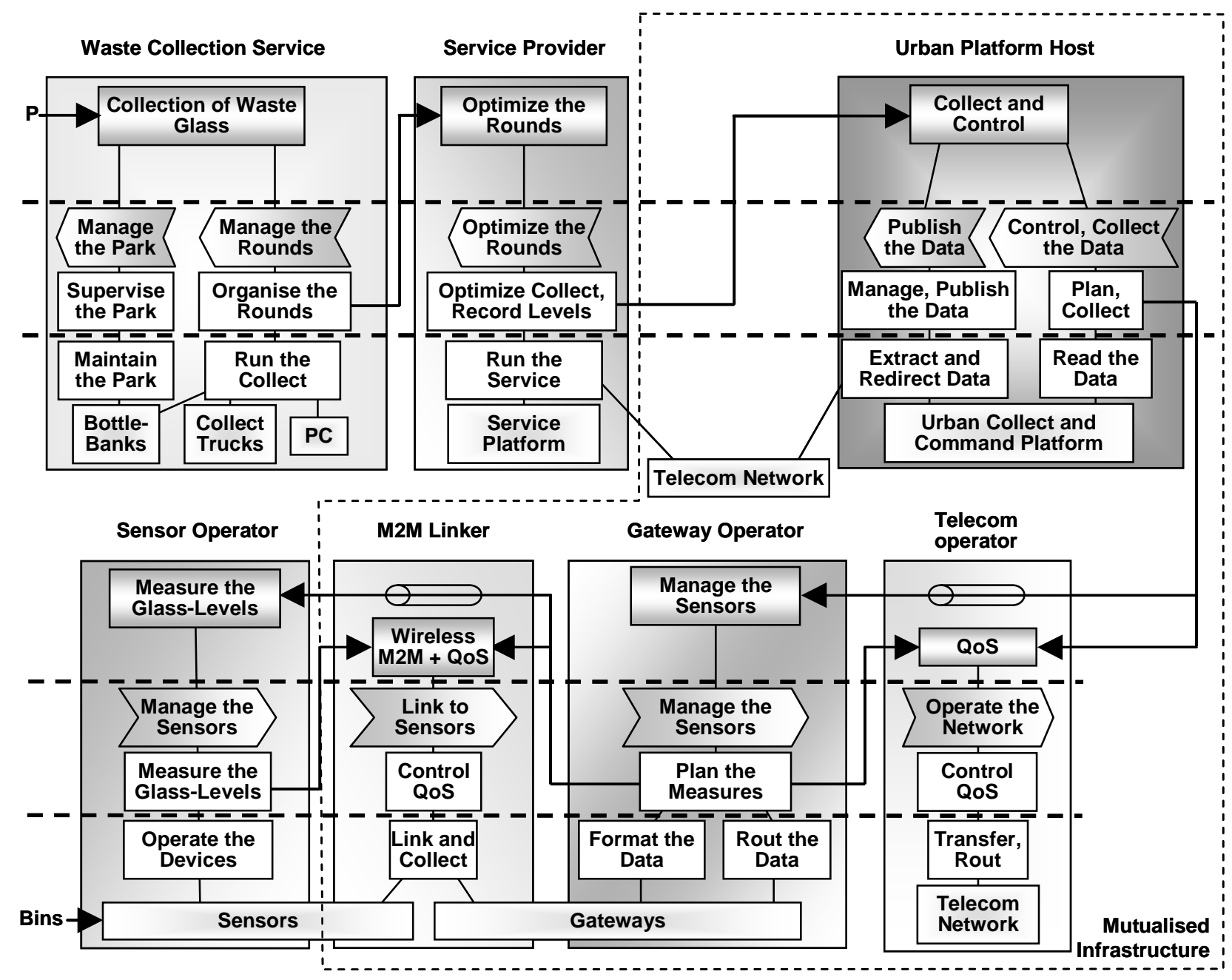

Figure 7: Case study: M2M-enhanced PSS network.

Figure 7 shows how the collaborative network works in the case of glass waste collection. The diagram starts on the top left with the waste collection company calling on the M2M PSS to help optimize the collection rounds. The SME providing the initial vertical service described in 4.2 is the service provider. It is now a member of the collaborative network. In order to optimize the rounds, the service provider has to obtain the glass levels from the sensors. To get this information it calls on the urban collect and control platform. It uses telecom services for this. Actually, many different SMEs participate in the platform, but to simplify the diagram, they are represented by one SME. The platform organises the management and safeguard of data coming from the sensors. It also handles legal questions concerning access to information, security and privacy. It collects the data from the gateway operator via the telecom network. Telecommunications influence the correct functioning of the network because GSM is used between the gateway and the platform. GSM is not always stable and QoS is important here. The gateways also participate in managing the sensors. Information is provided by the urban platform and the gateways organize local collection of the glass levels. The gateways exchange data with the sensors through a wireless M2M link, run by another SME. At this level QoS is insured by the M2M linker in coordination with the telecom operator. Finally the sensors measure the glass levels. 
It should be noted that some of the actors of the chain are more product-oriented, although they at least ensure the technical, legal and other evolutions of their products. Of course the real processes are more complicated and only the most critical activities and processes have been represented here in an overall view.

\subsection{Multi-service Applications}

It is now possible to apply the model to a multi-service case in the SensCity project. Three public utility services are proposed. The waste collection service detailed above; a service for monitoring pollution and noise at chosen locations in the city; and finally a support service for water works providing daily information on water consumption and possible leakage in the pipes. Figure 8 shows how the model illustrates the case. Functional representation is kept to the top-level in order to get a better overview and understanding of the common backbone.

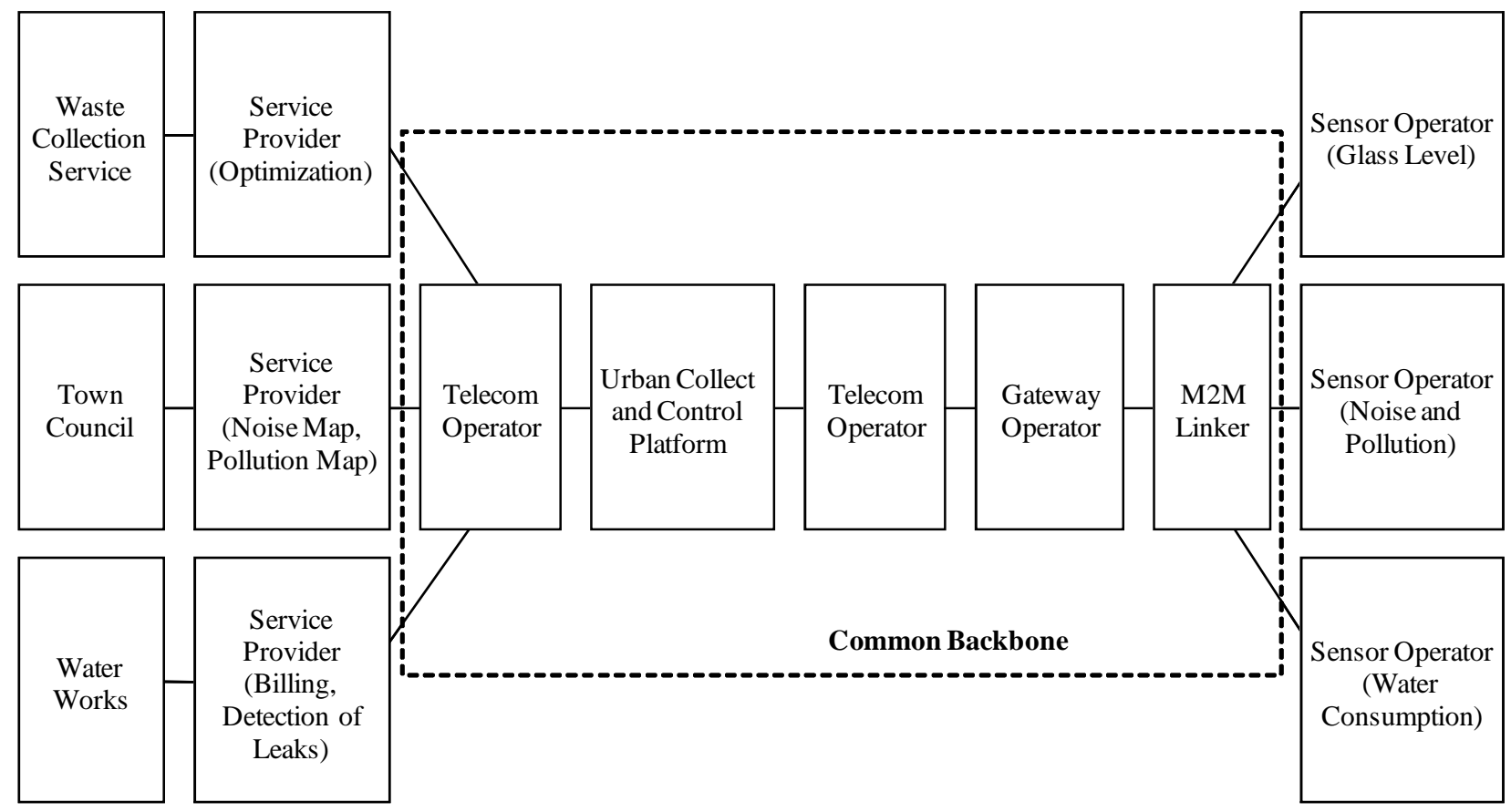

Figure 8: Top-level representation of multi-services with a shared backbone.

\subsection{Discussion}

A business model for collaborative networks proposing PSSs has been developed. SMEs join together behind an operator-integrator to deliver different services sharing a common backbone. The model is used to describe a basic service provided by a regional public enterprise (Figure 5) just as well as multi-services provided by a collaborative network (Figure 8).

The model displays some important strong points. The major advantage is the constant reference that is made to the firm providing each activity or physical support. It details the activities in the offer while conserving the information of the actors involved. In this way it helps establish the roles and responsibilities, facilitating design, operation as well as strategic management of the PSS network. When an SME leaves the network it is easy to identify the changes that have to be made and the missing activities that have to be replaced. At the same time it will facilitate the entry of new SMEs. Also, by defining precisely the responsibility of each actor in the provision of the overall service it facilitates smoother operation of the network. Trouble-shooting becomes simpler and the actor concerned is easily identified. Lastly, close proximity with other standard models ensures that the new model conserves the possibilities offered by these models. 
The model however does not take into account all the stakeholders. Stakeholders, like the local community, having interests that do not directly concern the provision of the PSS are not represented. The final user has a restricted role that needs more focusing. Finally, as with other flow-models, the complexity of the case can induce very complicated diagrams.

\section{The Collaborative Network of SMEs and Sustainability}

Vertical services are relatively easy to build but cannot be considered as optimal in terms of resources in an environmental perspective. The project SensCity seeks to build a collaborative network of SMEs behind a telecom operator to improve the environmental efficiency of the system (Lelah et al. 2011). Its goal is also to construct a sustainable M2M backbone capable of supporting a variety of services using data collected through a city-wide sensor network (Lelah et al. 2010). Today, sustainability often is confounded with environmentally friendly, and this point must first be clarified before examining some of the conditions for the network to be sustainable.

\subsection{Reference Models for Sustainability}

In the field of urban planning, Campbell (1996) considered sustainability as a dynamic issue that should be viewed across the three priorities and three resulting conflicts shown in Figure 9. Economic value must be distributed fairly while not degrading the ecosystem in the process. Economic growth can only be acceptable if it means significant reductions of input resources and if it be principally directed to activities demanding less energy and fewer resources. Fair distribution between generations has to be fair to poorer countries and amongst social groups within a country. Special care must be taken with the ecosystem as decisions taken on a local scale can affect ecosystems in other regions. The respect of future generations also implies that any development has to, at the least, respect a fair balance between economical, social and societal and environmental benefits under these conditions.

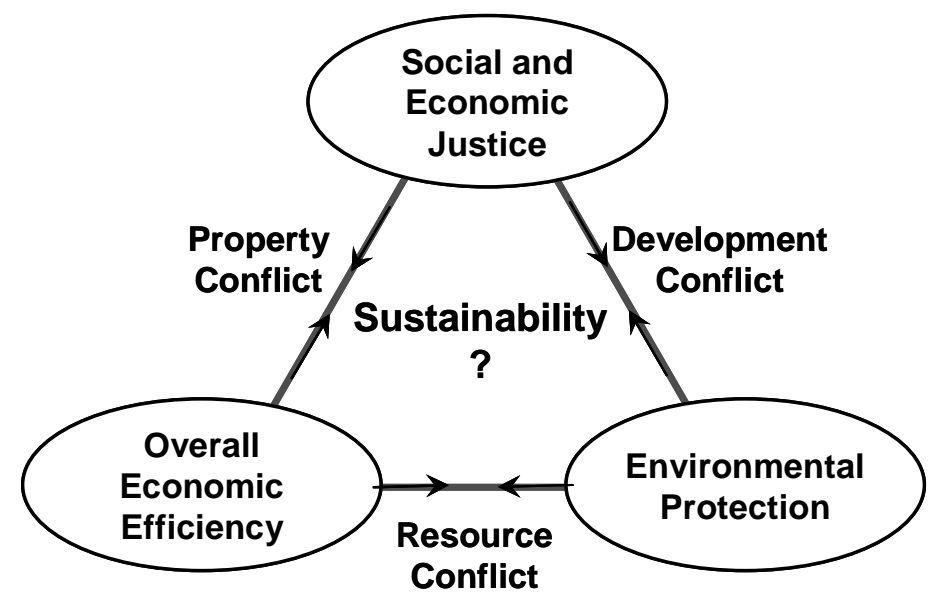

Figure 9: Sustainable Urban Development: Green, Profitable and Fair (Campbell, 1996).

There are few recognized frameworks or references to assess sustainability. Existing recognized tools can be very powerful but are often restricted to one aspect of sustainability. This is the case of available Life Cycle approaches that are either environmental or economical or social. Environmental issues are considered in Life Cycle Assessment, LCA (EU, 2006). Life Cycle Costing, LCC (Norris, 2001), treats questions concerning cost. Social LCA, S-LCA (Benoît et al. 2010), has recently been proposed to study social aspects.

Maxwell and van der Vorst (2003) proposed a method for sustainable product service development. In their model, normal economical criteria are integrated with environmental, social and functional criteria. The 
supply chain aspect of product manufacture is also incorporated. The focus shift from the individual firm towards the product supply chain is expected to lead to a paradigm shift in sustainability approaches in product manufacture. Chee Tahir and Darton (2010) described a method for assessing the degree of sustainability of a business operation, in terms of indicators related to the sustainability impacts of its particular activities. They proposed five steps to define the indicators and metrics for use: overview of business; definition of sustainability; system boundary; sustainability framework; verification and modification. The initial business overview included an inventory of the major processes, together with the associated process inputs and outputs, and stakeholder interests or concerns.

Considering that no widely accepted method taking into account all the aspects of sustainability is available today, the next section will overview particular important issues observed in the case study.

\subsection{Sustainability Issues in the Collaborative Network}

For collaborative networks, the question of sustainability is of important concern. This is especially true in the case of SensCity providing urban public utility services. For local-councils and other actors dealing with urban development, the issue is central. A preliminary analysis of sustainability within the SensCity network is presented here. Governance of the organization starts by identifying the stakeholders concerned by the products and services. Next, aspects of the three pillars of sustainability are considered: social; economical; and environmental. The model was built to facilitate dynamic adaptation of business offers within the service backbone. It describes the PSS proposed to local authorities and residents in urban settings. Therefore business offers, regional advantages and the users are finally included to complete this review of sustainability.

\subsubsection{Governance of the Organization}

The model does not identify all the stakeholders concerned by the project, but the major actors involved in the network. The project SensCity proposes deployment in an urban setting. Services will include waste collection, gas and water monitoring and pollution measurement. The OSPs concerned by each of the services are local authorities or semi-private firms, whereas the town council, representing the local population, remains the major interlocutor for the project. The model provides a clearer picture of the relative positions and interactions between the actors that can help to establish efficient and constant dialog amongst stakeholders.

\subsubsection{Social Responsibility}

By clarifying the activities of each partner the model provides an image of the responsibilities of the different actors. These are no longer individual firms with a restricted view of the impacts of their activities. They are now part of a common venture with responsibilities that open their vision and perspectives. Whether considering technical exigencies or environmental concerns, the project develops shared values concerning responsibility. In SensCity this desire had been expressed right from the beginning of the project by the participants. As for social responsibility, the collaborative network offers new opportunities. Quoted on the CAC $40^{3}$, the O-I is obliged by French law to produce an annual report on corporate social responsibility. The other SMEs are too small to expect from them the same level of communication. Close collaboration is a chance to share experiences and stimulate progress in the area for all the partners of the network, even for the SMEs.

\subsubsection{Economic Strengths and Weaknesses}

When entering the M2M consortium the SME concedes parts of its activities to other specialized firms. Instead of having to deal with everything it can concentrate on the real added value of its core skills. For example, local wireless communication is treated by an SME specialized in this question. The most recent advances are automatically available for the other partners to use. Each SME continuously updates to national and international standards and normalizations thereby ensuring economical competitiveness of the communication

\footnotetext{
${ }^{3}$ The CAC 40 is a benchmark of the French stock market index.
} 
modules and protocols. The advantages to be gained are evident, but the system has limits that must not be ignored. Dependency on SMEs is not without risk and targeted, shared protocols or technologies, such as communication protocols or other technical specifications, may fail to meet expectations. Another point is that the large firm leading the network can be long in taking decisions and tend to ignore the imperatives of the smaller partners. There is a large gap between an experimental project and a serious business offer and the smaller SMEs must take care to continue to develop their own markets outside the project so as not to end up trapped by $\mathrm{O}-\mathrm{I}$ hesitations.

\subsubsection{Environmental Benefits}

Pressed by the European Commission, governments and public opinion, new products and services developed today must integrate environmental concerns (e.g. WEEE ${ }^{4}, \mathrm{ErP}^{5}$ ). As a major firm, O-I cannot ignore the environmental impacts of its services. It must respond to society's expectations in order to maintain its reputation. A glance at Figure 8 suggests that the mutualised network shows potentials for reducing material needs of the backbone if it is correctly dimensioned. Within the network, O-I pushes the SMEs to review their products and services in a move towards eco-design. In the SensCity Project, SMEs are very receptive to this, and some had already taken steps internally in this direction before the start of the project. Mutual stimulation enhances this trend, especially from the more environmentally conscientious partners. Each partner can profit from the experience of others. It is nonetheless a large step to take with new skills to learn. During the SensCity project, exchanges with $\mathrm{O}-\mathrm{I}$ and the university partners are precious.

\subsubsection{Sustainable Business Offers}

From O-I's point of view, just one firm cannot develop all the applications necessary to invest new markets like M2M. O-I obviously cannot pretend that it will develop all the solutions internally and update them regularly. It cannot reasonably cover widely different fields like the optimization of waste glass collection, the provision of pollution and noise charts, monitoring water, and simultaneously be competitive in the variety of aspects dealing with communication and service platforms. O-I becomes more and more dependent on its supply chains. It needs some insurance that its suppliers meet certain standards and must have a view of future trends in the different fields. On the other hand, the success of the network of SMEs will allow O-I to create the conditions for a solid infrastructure capable of rapidly adapting to changing markets and needs. In return, many SMEs are capable of rapidly integrating new tools even though their small size does not allow them to penetrate deeply into the market alone. They too, have a lot to gain in credibility if the project succeeds. Initially, the network must be large enough to cover the vast panoply of services useful to the community. As the project grows it must be capable of national or even international development. The number and types of partners must not be rigid and easily adapt to changing situations. The model described above will facilitate the entry of new partners.

\subsubsection{Regional Advantages}

Instead of continuously piling up new vertical services, each with its own backbone, a shared backbone supporting multiple services could improve environmental performances of cities. When O-I makes an offer to a city or region it means that a complete network can be adapted. This could be an important asset for the region. When properly run, and if the choice of the services are made by the local authorities and not dictated solely by uncontrolled commercial offers, the backbone could support new local services providing new opportunities for jobs contributing to the wealth of the whole community. Finally the service rendered to residents would be both better and more environmentally efficient.

\footnotetext{
${ }^{4}$ EU legislation restricting the use of hazardous substances in electrical and electronic equipment (Directive 2002/95/EC) and promoting the collection and recycling of such equipment (Directive 2002/96/EC) has been in force since February 2003.

${ }^{5}$ EU legislation establishing a framework for the setting of eco-design requirements for energy-related products (Directive 2009/125/EC) has been in force since October 2009
} 


\subsubsection{User Satisfaction}

User needs and satisfaction are very important. Much of the information collected is private and this must be secured. O-I must establish transparency with clear contracts and the liabilities of the different actors must be properly defined. The network must provide free, accessible, installation without discrimination of any form. Good QoS has to be guaranteed. Safety aspects and other potentially hot spots like the level of electromagnetic waves must be treated right from the start by providing accurate and easily available information to all the residents concerned, directly or indirectly. Acceptability and appropriateness to user needs are fundamental, together with adequate training and information on the services provided and their consequences. Once again, this calls for establishing a clear picture of the relations between all the network actors, services and equipments used.

\subsection{Conclusion on sustainability issues}

The new model has the potential to clarify the organization of the network and especially the roles and the place of each actor. This knowledge is a key factor facilitating the identification of related sustainability issues and promoting awareness and responsibility amongst stakeholders. This paper argues that better representation can favour collaboration and mutual comprehension through shared experiences in all the three fields of sustainability. Additionally, this view will help understand the necessity of sustainable business offers coping with dynamically changing situations and that procure important regional benefits to its customers.

\section{Conclusion}

The transformation of single, distinct, vertical services into a complex network providing services, sharing a common backbone has been described. The article proposes an extension of existing models for products and services to the context of collaborative PSS networks. The model describes the service units and physical objects necessary to run the services. It conserves a view on the organization of the network and the relations between the partners. This is very useful for the design of the complete system and this representation can be exploited to understand the mechanisms of sustainability in a more global perspective. As an illustration, the model was applied to the case of glass waste collection in a move from the basic service to a more optimal frame in a network of urban public utility services. The different stages of the transformation have been described with the model. It draws attention to the fact that sustainability depends on the organization of activities built around physical objects and how these objects are used individually or collectively within the network. These issues have also been studied in the light of experience gathered from the SensCity project. Different points have been evoked covering the traditional pillars of sustainability as well as the actors and business offers represented in the project model. These are: governance of the organization; social responsibility; economical strengths and weaknesses; environmental benefits; sustainable business offers; regional advantages and user satisfaction. Future development of the model should integrate a more detailed description and role of the user and his activities during value creation. Co-creation of value is a key factor for PSS and it is important to provide a basis for exploring possibilities across the supply chain network. Additionally, a more systematic, comprehensive method for assessing sustainability issues should be developed in order to fully utilise the potential of the proposed PSS.

\section{Acknowledgements}

The authors would like to thank Xavier Boucher and Sophie Peillon, MESPROD, as well as Claude Pellegrin, COACTIS, and other participants of the GOSPI cluster in the Rhone-Alps region for the debates that led to the elaboration of the diagrams representing service relations used in this article. In addition, particular thanks go to all the SensCity project partners that have provided the inspiration for this work and with whom the authors have had very profitable exchanges. 


\section{References}

Alonso-Rasgado T., Thompson G., Elfström B., 2004. The design of functional (total care) products, Journal of Engineering Design. 15(6), pp. 515-540.

Benoît, C., Norris, G., Valdivia, S., Ciroth, A., Moberg, A., Bos, U., Prakash, S., Ugaya, C., Beck, T., 2010. The guidelines for social life cycle assessment of products: just in time! The International Journal of Life Cycle Assessment, 15(2), pp. 156-163.

Bourg, D. Buclet, N. (2005). L'économie de fonctionnalité. Changer la consommation dans le sens du développement durable. Futuribles, (313), pp. 27-38. [In French]

Bititci, U., Martinez, V., Albores, P., Mendibil, K., 2003. Creating and sustaining competitive advantage in collaborative systems: the what? and the how? Production Planning and Control. 14 (5), pp. 410-425.

Bititci, U. S., Ackermann, F., Ates, A., Davies, J. D., Gibb, S., MacBryde, J., Mackay, D., Maguirea, C., van der Meerb, R., Shaftib, F., 2011. Managerial processes: an operations management perspective towards dynamic capabilities. Production Planning \& Control: The Management of Operations, 22(2), p. 157.

Brezet, J.C., van Hemel, C.G., 1997. Ecodesign: a promising approach to sustainable production and consumption, United Nations Environmental Programme. UNEP Ecodesign manual.

Brundtland, G.H., 1987. Our Common Future, Report of the World Commission on Environment and Development, World Commission on Environment and Development.

Chee Tahir, A., Darton, R., 2010. The Process Analysis Method of selecting indicators to quantify the sustainability performance of a business operation. Journal of Cleaner Production, 18(16-17), pp. 1598-1607.

Camarinha-Matos, L. M., Afsarmanesh, H., Galeano, N., Molina, A., 2009. Collaborative networked organizations Concepts and practice in manufacturing enterprises. Computers \& Industrial Engineering, 57(1), pp. 46-60.

Campbell S., 1996. Green cities, growing cities, just cities? Urban planning and the contradictions of sustainable development. Journal of American Planning Association. 62, pp. 296-312.

Childe, S. J., 1998. The extended concept of co-operation. Production Planning \& Control: The Management of Operations, 9(4), pp. 320-327.

De Graaf, H. J., Musters, C. J. M., ter Keurs, W. J., 1996, Sustainable development: looking for new strategies. Ecological Economics. 16(3), pp. 205-216.

Derrouiche, R., Neubert, G., Bouras, A., Savino, M., 2010. B2B relationship management: a framework to explore the impact of collaboration. Production Planning \& Control: The Management of Operations. 21(6), pp. 528-546.

Dreyer, L., Hauschild, M., Schierbeck, J., 2006. A Framework for Social Life Cycle Impact Assessment. The International Journal of Life Cycle Assessment, 11(2), pp. 88-97.

EU, 2006. ISO-14040, Environmental management - Life cycle assessment - Principles and framework, EN ISO 14040:2006

EU, 2009, Study on the Competitiveness of the EU eco-industry. Final report. ENTR/06/054, pp. 156 -157, Available from: http://ec.europa.eu/environment/enveco/ [Accessed 22 March 2011].

Fresner, J. (1998). Cleaner production as a means for effective environmental management. Journal of Cleaner Production, 6(3-4), pp. 171-179.

Heiskanen, E., Halme, M., Jalas, M., Kärnä, A., Lovio, R., 2001, Dematerialization: The Potential of ICT and Services. Ministry of Environment. Helsinki.

Kimita, K., Yoshimitu, Y., Shimomura Y., Arai, T., 2009. A customer value model for sustainable service design. CIRP Journal of Manufacturing Science and Technology. 1(4), pp. 254-261.

Ki Moon, S., Simpson, T. W., Shu, J., \& Kumara, S. R. T., 2009. Service representation for capturing and reusing design knowledge in product and service families using object-oriented concepts and an ontology. Journal of Engineering Design. 20(4), p. 413.

Lelah, A., Mathieux, F., Brissaud, D., Gimeno, V., 2010, SensCity: a new project opening the way for sustainable services in the city based on a mutualised M2M infrastructure. Proceedings of the 2nd CIRP IPS ${ }^{2}$ Conference. pp. 99-106, Linköping, Sweden

Lelah, A., Mathieux, F., Brissaud, D., Contributions to eco-design of machine-to-machine product service systems: the example of waste glass collection. Journal of Cleaner Production, 19(9-10), pp. 1033-1044.

Lowe, E. A., Evans, L. K. (1995). Industrial ecology and industrial ecosystems. Journal of Cleaner Production, 3(1-2), pp. 47-53.

Maussang, N., Zwolinski, P., Brissaud, D., 2009, Product-service system design methodology: from the PSS - architecture design to the products specifications. Journal of Engineering Design. 20(4), p. 349-366.

Maxwell, D., van der Vorst, R., 2003. Developing sustainable products and services. Journal of Cleaner Production, 11(8), pp. 883-895.

Noori, H., Lee, W. B., 2004. Collaborative design in a networked enterprise: the case of the telecommunications industry. International Journal of Production Research, 42(15), 3041.

Norris, G. A., 2001. Integrating life cycle cost analysis and LCA. The International Journal of Life Cycle Assessment, 6(2), pp. 118-120.

Porter, M. E., 1998. Competitive advantage: creating and sustaining superior performance: with a new introduction. New York: Free Press. 
Sakao, T., Shimomura, Y., Lindahl, M. et Sundin, E. (2006). Applications of service engineering methods and tool to industries. In Brissaud, D., Tichkiewitch, S., Zwolinski, P., Innovation in life cycle engineering and sustainable development. Editions Springer, pp. 65-83.

Shimomura, Y., Hara, T., Arai, T., 2009. A unified representation scheme for effective PSS development. CIRP Annals Manufacturing Technology. 58(1), pp. 379-382.

Shostack, G. L., 1982. How to design a service. European Journal of Marketing. 16(1) pp. 49-63.

Simatupang, T.M. and Sridharan, R., 2005. An integrative framework for supply chain collaboration. International Journal of Logistics Management. 16 (2), 257-274.

Stahel, W.R., 1997. The Functional Economy: Cultural and Organizational Change. The Industrial green game: implications for environmental design and management. Richards, D. J., Engineering, N. A. O., Washington, DC: National Academy Press, pp. 91-100.

Tan, A., McAloone, T. C., Lauridsen, E. H., 2009. Reflections on product/service-system (PSS) conceptualisation in a course setting. International Journal of Design Engineering, Special issue on: "From Green Design to Eco-innovation and Sustainable Product Design.

Thoben, K., Jagdev, H. S., 2001. Typological issues in enterprise networks. Production Planning and Control: The Management of Operations, 12(5), p 421.

Tomiyama, T., 2001. Service engineering to intensify service contents in product life cycles. Proceedings of EcoDesign 2001. pp. 613-618, Tokyo, Japan.

Trkman, P., 2010. The critical success factors of business process management. International Journal of Information Management. 30(2), pp. 125-134.

Tukker, A., 2004. Eight types of product-service systems: eight ways to sustainability? Experiences from SusProNet. Business strategy and the environment. 13(4), pp. 246-260.

van Weenen, J. C., 1995. Towards sustainable product development. Journal of Cleaner Production, 3(1-2), pp. 95-100.

Verdouw, C. N., Beulens, A. J. M., Trienekens, J. H., van der Vorst, J. G. A. J., 2010. A framework for modelling business processes in demand-driven supply chains. Production Planning \& Control: The Management of Operations.

Zeithaml, V. et Bitner, M. (1986). Service marketing. McGraw-Hill, New York. 